\title{
CONTINUITY AND ADAPTABILITY: A COLLABORATIVE, ECO-INDUSTRIAL PARK (EIP)-FOCUSED APPROACH TO MANAGING SMALL TOWN COMMUNITY (STC) SUSTAINABILITY
}

\author{
RICHARD CAWLEY \\ Regents University, London.
}

\begin{abstract}
Outmigration, coupled with disruptive change - technological and climatic, present challenges for a small town community (STC) continuity and a concomitant adaptability imperative. The thesis of this paper is that the paramount need of STC is to attract and help to maintain SMEs (small and mediumsized enterprises) as the providers of jobs, and connected local economic benefits. However, urban planning faces concerns over their legitimacy, transparency, and the effects of what are perceived as (largely) politico-economic-driven and delayed planning processes. To address both needs and concerns, an original approach centred on collaborative decision-making by an eco-industrial park (EIP) stakeholder committee is explored. The connectivity of the local EIP tenants and stakeholder committee to an international EIP network enables adaptability and timely, informed STC decision making. To improve transparency and traceability in the latter, systematic, regular and scientific data gathering from its stakeholders is proposed. For this, a TRA/TPA-based research methodology is posited, and its application outlined. The discussion is based on research into urban planning, EIP and into SME management of eco-adaptation (EA), It is viewed as contributing to an important debate about urban planning processes, and to the change management needs of small towns. It has potential application to larger urban areas, and to cities. A list of recommendations for further research is provided. Keywords: adaptability, collaborative decision making, connectivity, continuity, EA, EIP, legitimacy, SME, stakeholder committee, STC, TRA/TPA research.
\end{abstract}

\section{INTRODUCTION}

'Business development is at the heart of a small town economic development strategy that can benefit from public policy in more ways than their larger counterparts. Activities should encourage new business start-ups, sustain and expand existing businesses, and increase innovation and entrepreneurship within the community'.

Knox P \& Mayer H (2013) Small Town Sustainability: 56

The capability of making timely decisions that have the support of key local stakeholder groups and, in probability, regional and or central government support, clearly depends on supportive horizontal (at the local level), and vertical communication. Given the collaboration required for the former, urban planning must be seen and sustainability-led. This could be, following the cogent argument of Lennon and Scott [1], a green infrastructure (GI) approach, both multifunctional and integrated, which the authors remind their readers 'seeks to understand, leverage, and value the different ecological, social and economic functions provided by natural systems to guide more efficient and sustainable land use and development 
patterns as well as protect ecosystems' (PCSD,1999,64). Public discourse about liveability [2], participative planning [3,4], Community-led planning (CP) [5], local co-production of neighbourhood planning) [6] and related discussion on deliberative democracy [7] reflect a prevailing localisation debate. This, in turn, contains themes regarding (local) concerns over the legitimacy, and [8-13], and over a 'politico-economic' model of decision-making lacking in transparency, being prone to delays, and intrinsically short-termist in looking for 'quick gains'. The need for any organisation to adopt a Kaizen approach of continual improvement, as well as to innovate, in fast-changing times sits uneasily with such perceptions or realities. Is 'public policy' and 'increase innovation and entrepreneurship within a community' (as evoked in the opening quote) an oxymoron in terms of either? Urban planners are also being entreated to move their focus 'from location and design' to social benefits [14], which appears congruent with the viewpoint [15] that collaborative planning is needed.

If such are some of the challenges and opportunities facing urban planners, then what are the underlying principles on which SMT stakeholders are to collaborate? Decision making, which balances the ' 3 Es' economic goals, environmental wisdom and social equity? Certainly the same authors, citing many sources on the theory of GI planning, invoke its four principles of respect-for-context, the primacy of the protection of GI assets and functions over land allocation, connectivity (the authors refer to spatial, scalar and institutional types of connectivity), and multi-functionality. The latter term refers to planners whose 'focus (is) on value in seeking to enhance multiple eco-system services, rather than 'addressing the provision of individual functions' (e.g. drainage, recreation etc.). GI's focus, they conclude, is on human well-being, and add that recent studies 'advocate a GI planning approach as a means to ensure sustained local and regional growth (LCPR, 2010)'.

Consideration of problems in balancing human benefit with ecological protection provides an echo to an earlier reflection [16] that 'the problem is that 'economic and environmental mechanisms for resource distribution, neither is a respecter of persons (and that)...the difficulty for the community or individual is that neither system favours humans'). The same author takes the view that 'The problem is that the concept of sustainable development is political rather than analytical' - the former not being known for the transparency or traceability (principles underpinning eco-sustainability) of its decision-making. This observation is germane to 'systematic and scientific' data-gathering approach here proposed, and later explored in its application to STC.

The research approach to this conceptual paper has been informed in various ways. Small Town sustainability was researched from the point of view of urban development and planning. Research [17], on market towns, provided the definition of STC size - 'a population somewhere between 2,000 and 30,000 (DETR/MAFF 2000)' has been followed for STAC here'. Its theoretical underpinning, follows that of Lennon and Scott (see earlier), namely that 'sustainability' management be premised on the balancing of economic, environmental and social goals - and be, fundamentally, innovative. Viewed as critical to STC sustainability the continued presence of a sustainable working population, and therefore local jobs - the effective management of EIP: SME tenant relationships were explored in their respective literatures. Continuity and adaptability needs were shown to provide common ground - this being shared with other co-member local stakeholder groups represented on an EIP committee. Finally, the need for transparency, traceability and relevance of decision making by the EIP stakeholder committee would be advanced, it is proposed, though a systematic and scientific approach to regular gathering and analysis of data from its members. Such would be congruent with previous reference (see above) to greater emphasis on the analytical, rather 


\section{Urban Regeneration and Sustainability}

than political processes as drivers, and, if well-managed, be seen, critically, as more worthy of local trust. There follows a summary discussion of the practical and the potential value of such analysis to STC's adaptability and continuity.

The paper will therefore follow the order of firstly, a brief introduction to EIP, then EIP management issues, with a focus on relationships with existing and potential tenant SMEs (these being the overwhelming majority of EIP tenants). In this, continuity and adaptability needs emerge as significant drivers for both 'sides', in which the promotion of innovation and stakeholder-based collaborative decision-making, are seen to play a significant role. EIP tenants' connectivity to an international EIP network (Fig 1) - including with other EIP domestically - would enable, it is argued, the rapid data and knowledge transfer needed to manage the disruptive change -especially from new technologies. Such 'knowledge links' would be valued by EIP tenants, keeping other EIP stakeholders updated for more relevant and timely decision making. Finally, to enable collaborative decision-making which addresses issues of legitimacy and provides potential long-term benefits to the STC), a process of regular and scientifically managed data collection from stakeholder groups is envisaged. It is proposed that a Theory of Reasoned Action (TRA) [18] - developed into a Theory of Planned Behaviour (TPB) [19] approach be considered. This is articulated here in equation form - and later explained, prior concluding remarks, and a brief listing of recommendations for further research. The TRA approach to understanding behavioural intention:

$$
B I=(A B) W_{1}+(S N) W_{2}
$$

where: $B I=$ behavioural intention $(A B)=$ one's attitude toward performing the behaviour, $\mathrm{W}=$ empirically derived weights $S N=$ one's subjective norm related to performing the behaviour [9] and where $A B=$ be where $\mathrm{b}$ equates the belief that something is or is not (the case), and/or that by doing $\mathrm{x}, \mathrm{y}$ results, and where $e$ represents (the influence of) values, e.g. as expressed in local priorities

When developed into the theory of planned action (TPB)) it can be, in its simplest form, expressed as the following mathematical function:

$$
B I=\left(W_{1}\right) A B[(b)+(e)]+\left(W_{2}\right) S N[(n)+(m)]+\left(W_{3}\right) P B C[(c)+(p)]
$$

$B I$ : Behavioural intention $A B$ : Attitude toward behaviour $(b)$ : the strength of each belief (e): the evaluation of the outcome or attribute $S N$ : Subjective norms $(n)$ : the strength of each normative belief $(\mathrm{m})$ : the motivation to comply with the referent $P B C$ : Perceived Behavioural Control $(c)$ : the strength of each control belief $(p)$ : the perceived power of the control factor $W^{\prime}$ : empirically derived weight/coefficient the extent that it is an accurate reflection of actual behavioural control, perceived behavioural control and, together with intention, be used to predict (actual) behaviour.

\section{EIP AND THE MANAGEMENT OF EIP: SME RELATIONS}

To consider a central role for EIP in STC sustainability, research was undertaken on the nature of EIP, and particular focus applied to a factor critical to EIP continuity : EIP:SME relationship management of tenant and potential tenant firms. These matters are discussed in turn, as also their common needs, with those of other local stakeholders, for continuity and adaptability needs. How the needs of all stakeholders are ascertained, these acting as collaborative co-members of an EIP-led committee is then explored, with reference to aforementioned TRA/TPB-based research processes. These, it is argued, can promote transparency and 
traceability in decision-making, and, if enacted regularly, provide also a valuable long-term local community narrative, and witness of a STC's history and cultural identity.

\subsection{EIP and SME tenants}

This section provides an introduction to EIP, their workings and relationship with SME in particular from a relationship management standpoint. EIP evolution can be traced back some 30 years from 'industrial estates or industrial clusters, science parks, corporate synergy systems, and as Environmental Management Systems (EMS) [20]. The formalisation of the present EIP concept is attributed [20] to the Indigo Development at Dalhousie University in 1992, with 17 self-labelled EIP in the USA by 1996. In contrast to Indigo United States EPA Research Project definition of EIP, in a detailed study [21], EIPs are linked clearly to ecoinnovation. The author from other definitions, chooses the definition the PSCD in the United States of an EIP as: "A community of businesses that cooperate with each other, and with the local community, to efficiently share resources with each other, to efficiently share resources (information, materials, water, energy, infrastructure and natural habitat) with the local community leading to economic gains, gains in environmental quality and equitable enhancement of human resources for the business and local community.' (196)

Here, EIP is viewed as designed in such a way that 'the way a company operates its production is taken into consideration when ensuring the park's general maintenance activity, so that it gets to be, through the synergy of different companies, an ecosystem from the point of view of resource use, and optimal energy consumption'. (84) This ecosystem needs to be sensitively managed as EIPs are not to constrain, by regulation, the often entrepreneurial behaviour of SME tenants. It is even to create an experimentalist culture in the EIP, and one involving the local community in the design of the park' [22]. The EIPs support role for SMEs as an educator and trainer in eco-adaptation (EA-see later) is clearly stated in the same research. The main managerial tasks of an EIP include promoting innovation, as also referred to more recently [23] as a core priority in SME-relationship management.

EIP collaborating with local public government can offer tenant enterprises the opportunity for large and long-term public sector contracts (e.g. waste disposal, energy-efficient lighting etc.). Significantly, these in turn can also contribute to the continuity of firm membership within the EIP, as tenant churn needs to be managed. Reference made to EIP's potential 'fragility' [24] leads some authors to counsel EIP management to think beyond survival, to long-term planning and continuity [25] and to where EIP and SME's interests clearly overlap.

This section has briefly explored EIP from a managerial perspective, with SME as potential and actual tenant enterprises. The EIP network acts as a link between regulators (central and provincial authorities) and tenant organizations - largely SME. EIPs are well-placed to take a holistic view of the EA process, and to marry central directives with local industry potential, and cultural ways. Here, EIPs can act as significant EA regional and local network hubs. As well as influencing existing, and anticipated/proposed regulations, EIP can play a significant role providing tenant firms a voice for enabling bottom-up input into these from these, as from other EIP committee members. EIP-SME collaboration can foster innovation and discussion of EA possibilities with direct benefit to the local STC, and adopt a shared perspective on the continuity and related risk management. This EIP-centred perspective is one side of a coin which explores EIP-SME relations, In the next section, the relationship is viewed from an SME managerial perspective. 


\section{Urban Regeneration and Sustainability}

2.1.1 Drivers, barriers to, and approaches to SME eco-adaptation

Discussion in this section refers to research relating to SME EA in terms of the forces promoting engagement - drivers and barriers to EA. Eco-start-ups are likely to embrace the same principles as defined earlier, which guide EIP management and goals. However other SME, for either supply-side or demand side reasons (or both), may realise they need to embrace eco-adaptation-and, it argued, might well identify benefits from EIP tenancy. Others may be managed in such a way as to not engage in EA, some reasons for which appear in this section.

Drivers

(i) Supply-side. It is widely agreed that SMEs are driven by economic goals and competitiveness, rather than by some balancing of those with social and environmental goals. That said, the overwhelming influence of bosses on SME can result in personal values-social and/or environmental influencing an offering. Some SME bosses want to 'do good', as well as do business. Eco-innovators fit within this category (though altruistic intentionally cannot be assumed). The authors identify a number of other drivers of SME EA: market opportunity, the influence of stakeholder groups [26], public sector organization requirements, eco-related government subsidies, regulation and taxes, industry codes of conduct and international standards, such as ISO 14001 The same researchers refer to 'eco-advantage', implying economic reward through EA, and also, potentially, a failure to compete in the absence of EA. Partner pressure can arise, for example, within a supply chain, when a large scale enterprise (LSE - see Interface Inc.) - 'focal firm' - tells suppliers to 'go green or lose the business' (!) Last but not least, technological advances drive eco-innovation (EI) and EA.

(ii) Demand side. These drivers of EA arise also, from evolving consumer expectations (see Lifestyle of Health and Sustainability (LOHAS) 'green consumer segmentation'). In adaptive organizations, SME employees too can bring 'bottom up' influence regarding EA quickly to an SME strategy discussion. Internal EA may be promoted within an enterprise in any area where managers' performance metrics cover environmental and social impacts. This can include application of triple bottom line auditing of performance, life cycle analysis (LCA) and other eco-metrics.

\subsection{Barriers}

A lack of awareness, limited access to information, to knowledge and technology, the effort of meeting regulatory requirements, a lack of skills and qualified personnel, limited access to finance, market and global supply chain access difficulties - such barriers to EA have been identified. A further barrier to EA is found when small firms are reluctant or/unable to pass their sustainability requirements upstream [27]. There may also be a mismatch between views and objectives of managers and skilled workers within firms implementing environmental design changes. A fear of creating supply chain instability in the search for new materials may also arise. Views in older studies [28] relate that small firms still have difficulty in identifying and acknowledging their environmental impact. These may still persist.

So as not to be constrained from normal entrepreneurial and innovative behaviours, SMEs will need, and benefit from, an EIP management and culture which is both, flexible, and experimentalist. Local legitimacy, enhanced by collaborative EIP stakeholder committee decision-making, can enhance the perceived legitimacy of members' - (including EIP tenants) 
actions locally, while supporting shared continuity needs and adaptability goals. Finally, an SME committing itself to relocation within an EIP, or exiting from one, will want to see risk shared in part at least by the EIP, such exits impacting on the EIP's own operation and, potentially, on its continuity. Given the various drivers and barriers to SME EA addressed, aforementioned connectivity to an international EIP information network, together with EIP management encouragement of eco-innovation, can help incentivise tenants toward continued tenancy. EIP management and tenants value such resulting continuity in their operations-one based on innovation and adaptability. An underpinning to such confidence and commitment is that collaborative EIP stakeholder committee deliberation be clearly based more on analysis of (robust research processes and) evidence than politicking and town hall oratory (!). This basis to urban planning decision making involving the systematic, regular and scientific gathering of EIP stakeholder constituency views- is outlined in a proposal in the next section.

\section{STC SUSTAINABILITY- APPLYING A TRA-ASSISTED APPROACH TO COMMUNITY DECISION-MAKING}

\subsection{Toward a more scientific approach to researching, and to addressing, local views and concerns}

Is it ever possible to accommodate the varying wishes of a multi-stakeholder- group? Some would argue not, but advances in communications' technologies, and big data analysis have already greatly facilitated survey administration and analysis. This enables timely decisionmaking, and, potentially, less 'hurriedness' in the face of sudden challenges from disruption, technological and climatic, as much as economic. The logic must be for STC, as EIP, to embrace the research potentialities of digitalisation, so as to expedite data collection, while choosing a methodology capable of gauging, with some degree of accuracy, the feelings, as well as the beliefs, of the local population constituencies under study. Local community expectations regarding the transparency, traceability (and evidence-based needs) and legitimacy of urban planning decisions, can be addressed through more evidence-based and local collaborative decision-making.

One research approach which can be employed for the latter purpose is that underpinned by the TRA/TPB equations stated earlier. These will here be related -in their parts- to an EIP management's research of its stakeholder constituencies' views. Clearly, in the space available, the explanation is to be taken as indicative of the potential value, and use, of the approach. The former will also rest in an administrative regularity likely to reduce high(er) response rates. The latter may lead, for example, to the development of a longitudinal research study, which, in turn, promotes the construction of a valuable evidence-based STC narrative, historical record, and point of cultural reference in decision-making.

The TRA/TPB equations identify various influences on how a respondent intends to behave $(B I)$-be it in voting, or in accepting or opposing a course of action, The approach helps identify dispositions ( $A B$ : attitudes) toward specified behaviours, perceptions of what is 'a normal' course of action, how much a respondent feels inclined to comply with others $(m)$, and how strongly s/he feels that by undertaking a certain behaviour (e.g. voting yes or no) they are 'meeting the norm' $(n)$. Relationships (weightings: $W$ ) between these potential influences are also deducible by the measurements -e.g. via Likert scales, and 'affect' ratings. In addition, within the TPB model, there is also the respondent's response ('control belief) to an overseeing 


\section{Urban Regeneration and Sustainability}

decision-making body, and her/his perception as to the perceived power of that (controlling) planning body $(P B C)$. In sum, a combination and interaction of attitudes, perceptions of selfaction (psychological) and self-to-others (sociological) data - these, and a respondent's relationship to those perceived as with 'controlling power' leads to 'behavioural intention'. This in turn can be viewed, if not as equating with actual behaviour, as having a strong relationship to the latter.

Applying such qualities to EIP data gathering from its stakeholders, areas of belief, value and expectation overlap can be identified, as also divergences. Results, being viewed within the EIP's ethos of balancing and making compatible economic, environmental and social goals, are also analysed as to the degree to which they accord or disaccord with stated and shared STC's sustainability goals. Perceived Behavioural Control (PBC) information can help to diagnose, as well as identify, causes of adverse responses to external influences. Examples of these are governmental bodies, technological 'threats', or even from competing EIP (though eco-collaboration would appear more likely).

For urban development consultants, the provision of such data as part of a longitudinal research process, can provide a more scientific basis for understanding STC culturally, and from which to draw objective conclusions -less impeded by the prevailing and political 'loudest voices'.

Such a longitudinal study provides also a basis for community reflection, for self-learning, and an aid to counter the selective memory not uncommonly found in town hall debate. Motivation-to-comply $(\mathrm{m})$ might serve also to indicate the degree of community cohesiveness- or lack of such, on any given issue. The instance of a heavy W3 weighting (i.e. on PBC) may promote, discussion of local feelings of powerlessness-and the sources of such feelings and beliefs.

The task of STM adopting a local regular data gathering process such as premised on TRA/ TPB may appear onerous, but one greatly facilitated by big data capture and processing. It can play an important role toward collaborative rationalism in urban planning decision making, offering more transparency and traceability of processes, and so potentially greater perceived legitimacy. Greater trust in planning processes, and in their local relevance (see $e$ in the equations here), is likely. EIP committee leadership can serve to emphasize the critical contribution of innovation and jobs to STC continuity and survival (the added 'C' of STC in this text not being redundant, but underlining that it is people and jobs, not spatial use and aesthetics, which it views as underpinning the current argument). Finally, in this original research on the topic, the focus is about an approach to the retention of a sustainable working age population for STC continuity. This STC capacity linked to that of adaptability in times of rapid and increasingly, disruptive, change, contributes to a growing literature connecting urban planning and participative decision-making.

Recommendations for Further Research

1. To explore the views amongst potential members of an EIP stakeholder committee as to the proposal outlined in this research

2. To consider relationships between small towns and EIP

3. To consider how the topic might relate to 'collaborative rationality' and the role of planners

4. To explore the proposal in terms of the creation of a local stakeholder recorded narrative as an instrument for learning, self-reflection and improved understanding of continuity and adaptability management 


\section{REFERENCES}

[1] Lennon, M. \& Scott, M., Delivering ecosystems services via spatial planning: reviewing the possibilities and implications of a green infrastructure approach. Town Planning Review, 85, pp. 563-587, 2014. http://dx.doi.org/10.3828/tpr.2014.35

[2] Massy, D., Liveable towns and cities: approaches for planners. Town Planning Review, 76, pp. 1-6, 2014.

[3] Hopkins, D., The emancipatory limits of participation in planning. Town Planning Review, 81, pp. 55-81, 2010. http://dx.doi.org/10.3828/tpr.2009.24

[4] Agger, A., Towards tailor-made participation: how to involve different types of citizens in participatory governance. Town Planning Review, 83, pp. 29-45, 2012. http://dx.doi.org/10.3828/tpr.2012.2

[5] Parker, G. \& Murray, C., Beyond tokenism? Community-led planning and rational choices: findings from participants in local agenda setting at the neighbourhood scale in England. Town Planning Review, 83, pp. 1-28, 2012. http://dx.doi.org/10.3828/tpr.2012.1

[6] Parker, G., Lynn, T. \& Wargent, M., Sticking to the script? The co-production of neighbourhood planning in England. Town Planning Review, 86, pp. 519-534, 2015. http://dx.doi.org/10.3828/tpr.2015.31

[7] Legacy, C., Curtis, C. \& Neuman, M., Adapting the deliberative democracy 'template' for planning practice. Town Planning Review, 86, pp. 319-340, 2014. http://dx.doi.org/10.3828/tpr.2014.20

[8] Brownhill, S., Participation and planning: dichotomies, rationalities and strategies for power. Town Planning Review, 787, pp. 401-428, 2007. http://dx.doi.org/10.3828/tpr.78.4.2

[9] Scattoni, P. \& Falco, E., The hidden factor in planning and local politics in Italy: the case of Tuscany. Town Planning Review, 83, pp. 47-67, 2012. http://dx.doi.org/10.3828/tpr.2012.3

[10] Tait, M., Building trust in planning professionals: understanding the contested legitimacy of a planning decision. Town Planning Review, 83, pp. 597-617, 2012. http://dx.doi.org/10.3828/tpr.2012.36

[11] Tait, M. \& Hansen, C-J., Trust and governance in regional planning. Town Planning Review, 84, pp. 283-312, 2013. http://dx.doi.org/10.3828/tpr.2013.17

[12] Chiodelli, F. \& Moroni, S., Corruption in land-use issues: a crucial challenge for planning theory and practice. Town Planning Review, 86, pp. 436-455, 2015. http://dx.doi.org/10.3828/tpr.2015.27

[13] Sturzacher, J. \& Shaw, D., Localism and practice-lesson from a pioneer neighbourhood plan. Town Planning Review, 86(5), pp. 587-609, 2015. http://dx.doi.org/10.3828/tpr.2015.34

[14] Howie, H., Can planners really deliver? Town Planning Review, 86, pp. 1-5, 2015. http://dx.doi.org/10.3828/tpr.2015.1

[15] Innes, J., Viewpoint: Collaborative rationality for planning practice. Town Planning Review, 87, pp. 1-4, 2016. http://dx.doi.org/10.3828/tpr.2016.1 
120 Urban Regeneration and Sustainability

[16] Batty, S., Planning for sustainable development in Britain. Town Planning Review, 77, pp. 20-41, 2006. http://dx.doi.org/10.3828/tpr.77.1.3

[17] Powe, N. \& Hart, T., Market-towns: understanding and maintaining functionality. Town Planning Review, 79, pp. 347-370, 2008. http://dx.doi.org/10.3828/tpr.79.4.2

[18] Fishbein, M. \& Azjen, I., Belief, Attitude, Intention and Behaviour: An Introduction to Theory and Research Practice, Addison-Wesley: Reading, MA, USA, 1975.

[19] Azjen, I., Theory of planned behaviour. Organizational Behaviour and Human Decision-Making Processes, 50, pp. 179-211, 1991. http://dx.doi.org/10.1016/0749-5978(91)90020-T

[20] Anbumozhi, V., Chandanie, A. \& Portugal, J., Boosting the environmental and economic competitiveness of SME clusters in Asia: policies and challenges, background paper prepared for the Regional Workshop on Eco-Industrial clusters, policies and challenges, Tokyo, Japan, 2009.

[21] Sarkar, A., Promoting eco-innovations to leverage sustainable development of ecoindustry and green growth. European Journal of Sustainable Development, 2(1), pp. 171-224, 2013.

[22] Gibbs, D. \& Deutz, P., Sustainability and the local economy: the role of eco-industrial parks. In Ecosites and the Implementation of European Union Environment and Sustainable Development Policies, eds. J. Dallemand \& L. Mottram, Department of Geography, Environment and Earth Science, University of Hull, UK, 2004.

[23] Roberts, P., The evolution, definition and purpose of urban regeneration. In Urban Regeneration: A Handbook, eds. P Roberts \& H Sykes, 2004.

[24] Dervojeda, K., Nagtegaal, F., Lengton, M. \& Daata, P., Eco-Industrial: Analysis of industry-specific framework conditions relevant for the development of world-class clusters. Report for European Cluster Observatory, The European Commission NL Agency, Utrecht, The Netherlands, 2013.

[25] Tudor, T., Adam, E. \& Bates, M., Drivers and limitations for the successful development and functioning of EIP's (eco-industrial parks): a literature review. Ecological Economics, 61(2-3), pp. 199-207, 2007.

http://dx.doi.org/10.1016/j.ecolecon.2006.10.010

[26] Esty, D. \& Winston, A., Green to Gold: How Smart Companies choose Environmental Strategy to Innovate, Create Value and Build Competitive Advantage, John Wiley and Son: New York, 2009.

[27] Jorgensen, A. \& Knudsen, J., Sustainable competitiveness in global supply chains -how do small Danish firms behave? The Copenhagen Centre for Corporate Responsibility, 2006.

[28] Vernon, J., Essex, S., Binder, D. \& Curry, K., The greening of tourism microbusinesses: Outcomes of four group investigations in South- East cornwall. Business Strategy and Environment, 12(1), pp. 46-49, 2003.

http://dx.doi.org/10.1002/bse.348 